American Medical Journal 3 (1): 8-13, 2012

ISSN 1949-0070

C 2012 Science Publications

\title{
Characteristics and Determinants of Primary Dysmenorrhea in Young Adults
}

\author{
${ }^{1}$ Shabnam Omidvar and ${ }^{2}$ Khyrunnisa Begum \\ ${ }^{1}$ Department of Food Science and Nutrition, \\ Faculty of Medical Sciences, University of Babol, Iran Mysore, India \\ ${ }^{2}$ Department of Food Science and Nutrition, \\ DOS in Food Science, Nutrition University of Mysore, Karnataka
}

\begin{abstract}
Problem statement: Dysmenorrhea is believed to be on rise affecting activities of women adversely. It was considered worthwhile to identify risk factors for dysmenorrhea, since such information is useful in designing management process. Approach: A Cross-sectional study was conducted on 500 healthy females aged 18-28 years. Standardized Self-reporting questionnaires were used to obtain relevant data. The categorical data was analyzed using Chi-sq, correlation and regression analyses by SPSS version 16. Results: Majority $(72.9 \%)$ of the participants experienced menstrual pain. More than 50\% dysmenorrheic subjects experienced pain every menstrual cycle. Among the factors studied menstrual flow, length of flow and family history exhibited positive association while family size had an inverse association to a significant extent $(\mathrm{p}=0.01)$. BMI, SFT did not exhibit significant effect, where as time spent in standing was significantly correlated to pain. Dysmenorrheic women scored significantly higher for all the subscales on menstrual attitude questionnaire, wherein certain components describing menstruation as debilitating event or predictability had high score significant at $1 \%$ level. Conclusion: Dysmenorrhea is becoming a highly debilitating event among young adult females with an increasing prevalence rate. The notorious determining factor may be the family history baring significant association to dysmenorrhea. Attitude towards menstruation and the posture is important contributory factors.
\end{abstract}

Key words: Dysmenorrhea, menstruation, factors, characteristics

\section{INTRODUCTION}

Menstruation is a normal biological process in woman of reproductive age (Sante and Sante, 1995). Often it is referred to cause physical discomfort and psychological upset. In most social structures it is surrounded by myths, superstitions and rituals since time immemorial. The modern scientific era has contributed a better understanding to its physiological importance, it is viewed with a scientific perspective nevertheless, differences in attitudes still persists among different population and culture groups. Since menstrual flow is a normal phase of female life and positive sign of good health, women should be encouraged to be normally active during menstruation (Moronkola and Uzuegbu, 2006).

Certain women experience pain during menstruation and is referred as dysmenorrhea. Primary dysmenorrhea is a common gynecological disorder in young women (Kennedy, 1997). Generally, it occurs within 6-12 months after encompassing menarche and characterized by crampy pelvic pain beginning shortly before or at the onset of menses lasting for 1-3 days (Durain, 2004). Pain occurs due to prostaglandins secretion that causes uterine smooth muscle to contract and set in the menstruation and expulsion of the endometrium (Campbell and McGrath 1997).

A variety of physiological, environmental and behavior factors are reported to influence dysmenorrhea. The confounding factors that have been referred frequently include-early menarche, younger age, low Body Mass Index (BMI), prolonged or aberrant menstrual flow, premenstrual somatic complaints, somatization, psychological disturbances, pelvic infections and smoking. Genetic influence is also known to affect prevalence and severity of dysmenorrhea (Latthe et al., 2006; Tonnin, 2002). Exertion and activity patterns are also found to influence dysmenorrhea. Epidemiological studies suggests that women participating in moderate recreational activity experience longer and more

Corresponding Author: Shabnam Omidvar, Department of Food Science and Nutrition, Faculty of Medical Sciences, University of Babol and Mysore Tel: 00919902363582 
variable cycles compared to sedentary women (Cooper et al., 1996; Harlow and Matanoski, 1991). The general consensus among women is that physical activities increase menstrual flows, therefore women tend to reduce their levels of physical activity during menstruation (Chiou et al., 2007; Lee et al., 2006; Im and Choe, 2001; Hill, 2003). Other than this, literature also indicate that menstruation is conceived as an overwhelmingly negative period, in fact a time when women must cope with considerable psychological and physical symptoms (Marianne and McPherson, 2004). The present study was planned with an objective to investigate the menstrual pattern among the young females from urban area and correlate the occurrence of dysmenorrhea with demographic variables, menstrual pattern, activity and attitude.

\section{MATERIALS AND METHODS}

The present study was of a Cross-sectional design conducted in urban areas from a major city in South India. The selected women were explained about the protocol and purpose of the study and were requested to complete the questionnaires to elicit information relating to demographic feature, menstrual characteristics, pain intensity and attitude towards menstruation.

Five hundred healthy young females aged 18-28 years formed the study population. They were selected from educational institutions offering higher secondary education, pre-university and under graduate courses. A purposeful sampling was adopted to select unmarried girls; also those who volunteered to give complete and correct information were included for the study.

Demographic assessment: The demographic information included family details relating to family size and type, chronological age and age at menarche. Parent's education, occupation, house type and possession of costly goods like vehicles, computer, TV, DVD, refrigerator, phones was also obtained and this information was used to compute Socio Economic Status (SES), it was designated as low, middle and high SES.

Assessment of menstrual characteristics: Menstrual regularity: Menstrual flow in equal intervals between 21 and 35 days was considered as regular (normal) menstruation (Bernis et al., 1999).

Menstrual blood flow: The quantity of menstrual flow usually experienced was recorded by each participant as per the method suggested by Higham and Shaw (1990). This was indicated based on the size of stain and number of pads used per day during the menstruation. The extent of blood loss was expressed as low, moderate, or heavy.
Identifying dysmenorrheic females: Those females, who experienced pain in the abdominal, groin and lumbar regions on the day before or on the first day of menstruation, were considered as dysmenorrheic (Liu et al., 2007).

Pain intensity: The Numerical Pain Scale developed by McCaffery and Beebe (1993) was used for assessing pain intensity.

Anthropometric assessment: All the participants were measured for linear height and body weight. Height measuring scale was used to measure height to the nearest of $0.1 \mathrm{~cm}$. Body weight was measured using a battery operated digital balance(Glan Electronic Scale) the balance was checked for its accuracy each time before use, measurements were made to the nearest of $0.1 \mathrm{~kg}$. This information was used to compute BMI.

Skin Fold Thickness (SFT) was also measured at triceps, using SLIMGUIDE caliper to the nearest of one millimeter. Standard protocols as described by Jelliffe (1966) were employed for all the measurements.

Physical activity: Time spent on usual activities for 24 $\mathrm{h}$ during the normal days was obtained through recall method as suggested by WHO FAO/WHO/UNU, 1985. The pattern and type of exercise performed in the past one week was also collected. The information was computed as the duration of work done in different postures such as sitting, standing, walking, lying down and sleeping.

Menstrual attitude: Menstrual attitude questionnaire of Brooks-Gunn and Ruble (1980) and modified was adopted. This schedule carried 22 items with six dimensions for menstruation, i.e., as a debilitating event, a bothersome event, a natural event, anticipation and prediction of the onset of menstruation, denial of any effect of menstruation and embarrassment about menstruation. Each item was scored from disagree strongly to agree strongly.

The research protocol was approved by the Ethical Committee, University of Mysore.

The data was analyzed using SPSS for Windows version 16. Descriptive statistics was used to determine mean and percentages. The categorical data was analyzed using Chi-sq, correlation and regression analyses.

\section{RESULTS}

Subjective information is presented in Table 1, the participants were in the age group of 18-28 years with a mean age of $21 \pm 1.65$ years. No significant difference in age was noted between dysmenorrheic and non dysmenorrheic women; however it is of concern that more than 50\% dysmenorrheic subjects experienced pain every menstrual cycle. 
Am. Med. J. 3 (1): 8-13, 2012

Table 1: Socio-demographic characteristics of females by status of dysmenorrhea

\begin{tabular}{|c|c|c|c|c|c|}
\hline $\begin{array}{l}\text { Socio demographic } \\
\text { variables }\end{array}$ & & $\begin{array}{l}\text { Dysmenorrheic } \\
\mathrm{N}(\%)\end{array}$ & $\begin{array}{l}\text { Non dysmenorrheic } \\
\mathrm{N}(\%)\end{array}$ & $\begin{array}{l}\text { Total } \\
\mathrm{N}\end{array}$ & $\begin{array}{l}\text { Chi- } \\
\text { square }\end{array}$ \\
\hline Distribution & & $363(72.9)$ & $135(27.1)$ & 498 & \\
\hline \multirow[t]{2}{*}{ Age (Years) } & $18-21$ & $185(51)$ & $66(48.9)$ & 251 & $0.170^{\mathrm{n}}$ \\
\hline & $>21$ & $178(49)$ & $69(51.1)$ & 247 & \\
\hline \multirow[t]{3}{*}{ SES } & Low & $99(27.3)$ & $38(28.1)$ & 137 & $1.428^{\mathrm{n}}$ \\
\hline & Middle & $221(60.9)$ & $76(56.3)$ & 297 & \\
\hline & High & $43(11.8)$ & 21(15.6) & 64 & \\
\hline \multirow[t]{3}{*}{ Family size } & $\leq 4$ & $204(56.2)$ & $66(48.9)$ & 270 & 7.999* \\
\hline & $5-8$ & $152(41.9)$ & $60(44.4)$ & 212 & \\
\hline & $>8$ & $7(1.9)$ & $9(6.7)$ & 16 & \\
\hline \multirow[t]{3}{*}{ Type of family } & joint & $45(12.5)$ & $16(11.9)$ & 61 & $0.607^{\mathrm{n}}$ \\
\hline & Nuclear & $304(84.5)$ & $112(83.6)$ & 416 & \\
\hline & Extended & 11(3) & $6(4.5)$ & 17 & \\
\hline
\end{tabular}

Table 2: Menstrual characteristics, family history and work pattern of subjects with/without dysmenorrhea

\begin{tabular}{|c|c|c|c|c|}
\hline Menstrual characteristics & Dysmenorrheic N (\%) & Non dysmenorrheic N (\%) & Total & Chi-square \\
\hline \multicolumn{5}{|l|}{ Cycle length } \\
\hline \multirow[t]{4}{*}{$<21$ days } & $12(3.4)$ & $7(5.4)$ & 19 & $4.492^{\text {ns }}$ \\
\hline & $21-27$ & $144(40.7)$ & $59(45.7)$ & 203 \\
\hline & $28-35$ & $168(47.4)$ & $58(45)$ & 227 \\
\hline & $>35$ & $30(8.5)$ & $5(3.9)$ & 35 \\
\hline \multicolumn{4}{|l|}{ Blood flow } & $7.761 *$ \\
\hline Low & $85(23.5)$ & $48(35.8)$ & 133 & \\
\hline Moderate & $96(26.5)$ & $32(23.9)$ & 128 & \\
\hline Heavy & $181(50)$ & $54(40.3)$ & 235 & \\
\hline \multicolumn{5}{|l|}{ Length of flow (days/ cycle) } \\
\hline$\leq 4$ & $144(40)$ & $73(54.5)$ & 217 & $8.423 *$ \\
\hline $5-6$ & $195(54.2)$ & $56(41.8)$ & 251 & \\
\hline$\geq 7$ & $21(5.8)$ & $5(3.7)$ & 26 & \\
\hline \multicolumn{5}{|l|}{ Regularity of periods } \\
\hline Yes & $310(85.6)$ & $120(88.9)$ & 430 & $0.891^{\mathrm{ns}}$ \\
\hline No & $52(14.4)$ & $15(11.1)$ & 67 & \\
\hline \multicolumn{5}{|c|}{ Family history of menstrual pain } \\
\hline Yes & $243(68.4)$ & $55(42)$ & 298 & $28.2 * * *$ \\
\hline No & $112(31.6)$ & $76(58)$ & 188 & \\
\hline
\end{tabular}

Table 3: Distribution of subjects into BMI category and SFT

\begin{tabular}{|c|c|c|c|c|c|}
\hline \multirow[b]{2}{*}{$\begin{array}{l}\text { Anthropometric } \\
\text { parameters }\end{array}$} & \multicolumn{4}{|c|}{ Menstrual pain } & \multirow[b]{2}{*}{ Chi-square } \\
\hline & \multicolumn{2}{|c|}{$\begin{array}{l}\text { Dysmenorrheic } \\
\mathrm{N}(\%)\end{array}$} & \multicolumn{2}{|c|}{$\begin{array}{l}\text { Non dysmenorrheic } \\
\mathrm{N}(\%)\end{array}$} & \\
\hline \multicolumn{6}{|l|}{ BMI } \\
\hline$<18.50$ & 97 & 26.7 & 44 & 32.6 & $3.542(3)$ \\
\hline $18.50-24.99$ & 218 & 60.0 & 78 & 57.8 & $\mathrm{p}=0.315$ \\
\hline $25.00-29.99$ & 43 & 11.8 & 10 & 7.4 & \\
\hline$\geq 30.00$ & 5 & 1.4 & 3 & 2.2 & \\
\hline \multicolumn{6}{|l|}{ SFT } \\
\hline & Mear & & Mea & & Correlation \\
\hline & 14.48 & & 14.5 & & $\mathrm{r}=0.890$ \\
\hline
\end{tabular}

Table 4: Correlation Coefficient between different position and dysmenorrhea

\begin{tabular}{|c|c|c|c|}
\hline \multirow[b]{2}{*}{$\begin{array}{l}\text { Different } \\
\text { positions }\end{array}$} & \multicolumn{2}{|c|}{$\begin{array}{l}\text { Mean } \pm \text { SD total time } \\
\text { for different position in two groups }\end{array}$} & \multirow[b]{2}{*}{$\begin{array}{l}\text { Pearson } \\
\text { correlations }\end{array}$} \\
\hline & Dysmenorrheic & $\begin{array}{l}\text { Non } \\
\text { dysmenorrheic }\end{array}$ & \\
\hline Sitting & $418.07 \pm 144$ & $414.23 \pm 133$ & 0.012 \\
\hline Standing & $205.52 \pm 104$ & $184.42 \pm 89$ & $-0.099 *$ \\
\hline Walking & $102.02 \pm 67$ & $93.91 \pm 50$ & -0.065 \\
\hline Sleeping/lying & $522.88 \pm 105$ & $537.26 \pm 96$ & 0.064 \\
\hline Working & $165.77 \pm 107$ & $172.61 \pm 118$ & 0.026 \\
\hline
\end{tabular}

The percentage distribution of women into low, middle and high SES was also essentially similar in the two groups. Majority of the selected women belonged to low and middle SES. Family size of the participants varied between less than 4 to more than 8 members, large families were less prevalent. Chi-sq analysis exhibited a significant association between family size and dysmenorrhea $(\mathrm{p}=0.01)$.

Table 2 presents the menstrual characteristics and family history of dysmenorrhea. 
Am. Med. J. 3 (1): 8-13, 2012

Table 5: Mean and group differences of attitudes toward menstruation

\begin{tabular}{|c|c|c|c|c|c|}
\hline MAQ subscales & Group & $\begin{array}{l}\text { Group } \\
\text { Dysmenorreic }\end{array}$ & $\begin{array}{l}\text { Non } \\
\text { dysmenorrheic }\end{array}$ & $\mathrm{t}$ & $\mathrm{p}$ \\
\hline Menstruation as a debilitating event Mean \pm SD & $3.37 \pm 1.1$ & $3.45 \pm 0.06$ & $3.02 \pm 0.1$ & -2.304 & \\
\hline Menstruation as a bothersome event Mean \pm SD & $3.42 \pm 0.85$ & $3.46 \pm 0.85$ & $3.24 \pm 0.94$ & 0.022 & \\
\hline Menstruation as a natural event Mean \pm SD & $3.71 \pm 1.07$ & $3.7 \pm 1.09$ & $3.71 \pm 1.11$ & 0.162 & 0.871 \\
\hline $\begin{array}{l}\text { Anticipation and prediction of the onset of } \\
\text { menstruation Mean } \pm S d\end{array}$ & $3.91 \pm 1.35$ & $4.06 \pm 1.32$ & $3.22 \pm 1.56$ & -5.873 & 0.000 \\
\hline Denial of any effect of menstruation Mean \pm SD & $3.53 \pm 1.37$ & $3.15 \pm 1.71$ & $2.92 \pm 1.77$ & -1.234 & 0.218 \\
\hline Embarrassment about menstruation Mean \pm SD & $3.15 \pm 1.28$ & $3.17 \pm 1.29$ & $2.84 \pm 1.49$ & -2.413 & 0.016 \\
\hline
\end{tabular}

Table 6: Relationship between certain subjective factors on occurrence of dysmenorrhea

\begin{tabular}{llll}
\hline Variables & $\beta$ & Adj. $^{2}$ & $\mathrm{P}$ \\
\hline Family size & -0.096 & 0.007 & 0.033 \\
Menstrual blood flow & 0.117 & 0.012 & 0.009 \\
Length of flow & 0.126 & 0.014 & 0.005 \\
Family history of menstrual pain & 0.241 & 0.056 & 0.000 \\
\hline
\end{tabular}

It is evident that $48-90 \%$ of women had the cycle length of 21-27 and 28-35 days respectively. No significant differences in the cycle length were found between women with and without dysmenorrhea $\left(\chi^{2}=4.492\right)$. Blood flow and length of flow appeared to be significantly associated with dysmenorrhea, $50 \%$ of dysmenorrheic women reported to experience heavy blood flow and $26.5 \%$ had moderate flow as against the non dysmenorrheic (40.3 and 23.9\%) females. Majority of dysmenorrheic females experienced more menstrual days of flow (5-6 and $\geq 7$ days), which exhibited significant association according to the chi. Sq. analysis $\left(\chi^{2}\right.$ 8.423). All the participants regardless of dysmenorrhea had regular periods.

Table 3 provides the distribution pattern of selected subjects into the BMI categories. Majority (60 and $57.8 \%$ ) of dysmenorrheic and non dysmenorrheic women respectively had BMI in the normal range (18.5-24.99). Nearly 27 and 33\% of women had BMI less than 18.5 indicating Chronic Energy Deficiency (CED), while 13.2 and $9.6 \%$ of women were overweight and obese. It is worthwhile to highlight that a higher percent of dysmenorrehic women were in this category. However the distribution of women with and without dysmenorrhea into various BMI categories was not significant statistically at 5\% level. There was not meaningful difference in mean of SFT between two groups.

Table 4 provides data regarding the usual daily activity pattern of the participants. Pearson`s correlation was performed to identify the association between time spent in activities such as standing, sitting, walking, lying down or sleeping and occurrence of dysmenorrhea. The mean time spent in standing and walking was higher among dysmenorrheic girls as compared to non-dysmenorrhic, standing time was found to be negatively correlated to dysmenorrhea significantly. It appears that the non dysmenorrhic females' work in a more leisurely manner, since sleeping time was higher while walking and standing time was comparatively low, this probably make them fit for working longer time.

Table 5 presents mean scores for attitudes towards menstruation, as it is evident from the table, the mean values for all subscales for dysmenorrheic women were significantly higher than those scored by non dysmenorrheic women. Scores for subscales such as "debilitating event" and "prediction of the onset of menstruation" were extremely significant at $1 \%$ level. On the other hand scores for other subscales except for "Menstruation as a natural event" and "Denial of any effect of menstruation" were significant at 5\% level, indicating that dysmenorrhea is influenced by an array of psychological factors.

Table 6 Certain selected subjective factors such as family size, menstrual flow, length of flow, family history for menstrual pain and occurrence of dysmenorrhea were subjected to correlation test. Although all the selected variables correlated significantly to the occurrence of dysmenorrhea in the selected women, family history exhibited extremely significant correlation.

\section{DISCUSSION}

Dysmenorrhea is being recognized as an important debilitating period for females. Studies from different regions indicate a rise in its prevalence rate (Agarwal and Agarwal, 2010). The cause of primary dysmenorrhea has not been clearly elucidated (Davis and Westhof, 2001). Less is known about the nonbiological factors in the etiology of primary dysmenorrhoea. Demographic characteristics are often referred to influence dysmenorrhea, especially the chronological age, menarche age and SES. In the present study family size was seen to have a significant effect, nevertheless, age and SES did not exhibit significant association. Although the effect seen between family size and dysmenorrhea was mild, it was surprising that females from small families were more inflicted than those from large families; the reason for such an observation is difficult to explain. Studies from 
different regions covering a large number of adolescent population reported socioeconomic status and literacy to have a positive correlation with dysmenorrheal (Klein and Litt, 1988; Patel et al., 2006), contrary to this, Ohde et al. (2008) reported no association to income or education with dysmenorrheal.

Menstrual characteristics are known to be one of the risk factors for dysmenorrhea, wherein, the important ones being length of flow and menstrual blood loss (Balbi et al., 2000). Our findings also revealed similar results, since both length of flow and menstrual blood loss were found to be significantly associated to the occurrence of dysmenorrhea. Results from other studies have supported our findings (DiCintio et al., 1997). Genetic predisposition to dysmenorrhea was found to be a predominating factor in the present group; the results indicate that family history is a vital sign for predicting the occurrence of dysmenorrhea among the female child. According to genetic studies, genotypes were found to have a significant association with risk of recurrent dysmenorrhea (Di et al., 2000; Liu et al., 2007).

\section{CONCLUSION}

Our results also revealed that cycle length and regularity of menstruation did not exhibit significant association to dysmenorrhea. However, fact is that relatively higher proportions of the selected females in dysmenorrheic group had longer cycle length than the non dysmenorrheic females suggesting cycle length to exert an effect in menstrual pain. Both dysmenorrheic and non dysmenorrheic females were found to experience regular menstrual periods. A small proportion of the participants reported to have experienced irregularity. It is relevant to mention that, the primary dysmenorrhea may essentially be due to hormonal effects causing higher levels of circulating prostaglandins.

According to the Ozerdogan et al. (2009) dysmenorrhea was 1.5-times higher in underweight women compared to overweight/obese women (OR 1.52 ; 95\% CI 0.99-2.33). Other studies reported that adopting weight management programs also caused an increase in menstrual pain (Montero et al., 1996). However, in contrary our study did not find an association between BMI and SFT to the occurrence of dysmenorrhea, studies reported by Ohde et al. (2008) supported our findings (Ohde et al., 2008).

Importance of attitude towards dymsmenorrhea has been a focus of study from various countries and realized that a significant cross-cultural difference exists. It is often reported that psychological status influences the occurrences of debilitating events (Wang et al., 2004; Lori et al., 2000). The readiness for menstrual event reflects the attitudes of women towards themselves and in turn their self esteem. Hoerster et al. (2003) in their comparison between American and Indian women in knowledge and attitude towards menstruation found American women to score significantly higher for preparedness and knowledge for menstruation than the Indian women. On the other hand Indian women scored significantly higher for their positive attitude towards menstruation (Hoerster et al., 2003). Results from other studies coincided with our findings that majority $(92.2 \%)$ of females regardless of age believed menstruation was a natural event also $71.1 \%$ believed that the onset of menstruation could be anticipated (Hoerster et al., 2003; Lu, 2001).

\section{ACKNOWLEDGMENT}

Researchers are grateful to the all participants and also would like to thank Dr. Ram Bahadur Singh for his support and his cooperation in this study.

\section{REFERENCES}

Agarwal, A.K. and A.A. Agarwal, 2010. Study of dysmenorrhea during menstruation in adolescent girls. IJCM, 35: 159-164. DOI: 10.4103/09700218.62586

Sante, F.E.B., M.E.B. Sante,1995. Healthy Women, Healthy Mothers: An Information Guide. Family Care International, Inc.

Balbi, C., R. Musone, A. Menditto, L.D. Prisco and E. Cassese et al., 2000. Influence of menstrual factors and dietary habits on menstrual pain in adolescence age. Eur. J. Obstetrics Gynecol. Reproductive Biol., 91: 143-148.

Bernis, C., P. Montero and S. Castro, 1999. Menstrual pain, menarcheal age and lifestyles in Spanish adolescents. Int. J. Anthropology, 14: 85-97. DOI: 10.1007/BF02443889

Brooks-Gunn, J. and D.N. Ruble, 1980. The menstrual attitude questionnaire. Psychosom, Med., 42: 503-11.

Campbell, M.A. and P.J. McGrath, 1997. Use of medication by adolescents for the management of menstrual discomfort. Arch Pediatr Adolesc. Med., 151: 905-912.

Chiou, M.H., H.H. Wang, Y.H. Yang, 2007. Effect of Systematic Menstrual Health Education on Dysmenorrheic Female Adolescents' Knowledge, Attitudes and Self-Care Behavior. Kaohsiung J. Med. Sci., 23: 183-190.

Cooper, G.S, D.P. Sandler, E.A. Whelan and K.R. Smith, 1996. Association of physical and behavioral characteristics with menstrual cycle patterns in women age 29-31 years. Epidemiology, 7: $624-628$. 
Davis, A.R. and C.L. Westhof, 2001. Primary dysmenorrhea in adolescent girls and treatment with oral contraceptives. J. Pediatr Adolesc Gynecol, 14: 3-8.

DiCintio, E., F. Parazzini, L. Tozzi, L. Luchini and R. Mezzopane et al., 1997. Dietary habits, reproductive and menstrual factors and risk of dysmenorrhoea. Eur. J. Epidemiology, 13: 925930. DOI: 10.1023/A:1007427928605

Durain, D.C.N.M., 2004. Primary dysmenorrhea: assessment and management update. J. Midwifery Womens Health, 49: 520-528. DOI: 10.1016/j.jmwh.2004.08.013

Lori, G.B., L. Grace, S. R. Susan, Y.H. James, 2000. menstrual disorders and occupational, stress and racial factors among military personnel. J. Occup. Environ. Med., 42: 871-881.

Harlow, S.D. and G.M. Matanoski, 1991. The association between weight, physical activity and stress and variation in the length of the menstrual cycle. Am. J. Epidemiol., 133: 38-49.

Higham, J.O.B.P. and R. Shaw, 1990. Assessment of menstrual blood loss using a pictorial chart. Br. J. Obstet. Gynaecol, 97: 734-739.

Hill, P.F., 2003. African Americans. In: Caring for Women Cross-Culturally 2003, Hill, P.F., J.G. Lipson and A.I. Meleis (Eds.). F.A. Davis, Philadelphia, pp: 11-20.

Hoerster, K.D., J.C. Chrisler and J.G. Rose, 2003. Attitudes toward and experience with menstruation in the US and India. Women Health, 38: 77-95. DOI: $10.1300 / J 013 v 38 n 03 \_06$

Im, E.O. and M.A. Choe, 2001. Physical activity of Korean immigrant women in the U.S.: needs and attitudes. Int. J. Nursing Stud., 38: 567-577.

Jelliffe, D.B., 1966. The assessment of the nutritional status of the community (with special reference to field surveys in developing regions of the world). Monogr Ser. World Health Organ., 53: 263-271. PMID: 4960818

Kennedy, S., 1997. Primary dysmenorrhea. Lancet, 349: 1116.

Klein, J.R. and I.F. Litt, 1988. Epidemiology of Adolescent Dysmenorrhea. Pediatrics, 68: 661-664.

Latthe, P., L. Mignini, R. Gray, R. Hills and K. Khan, 2006. Factors predisposing women to chronic pelvic pain: systematic review. BMJ, 332: 749-755. DOI: $10.1136 / \mathrm{bmj} .38748 .697465 .55$

Lee, L.K., P.C.Y. Chen, K.K. Lee and J. Kaur, 2006. Menstruation among adolescent girls in Malaysia: A cross-sectional school survey. Singapore Med. J., 47: 869-874.
Liu, H., F. Yang, Z. Li, C. Chen, Z. Fang et al., 2007. Passive smoking, Cyp1A1 gene polymorphism and dysmenorrhea. Reprodu. Toxicol., 24: 114-119. DOI: 10.1016/j.reprotox.2007.04.069

Lu, Z.Y.J., 2001. The relationship between menstrual attitudes and menstrual symptoms among Taiwanese women. J. Adv. Nurs., 33: 621-628. DOI: 10.1046/j.1365-2648.2001.01705.x

Marianne, E. and B. McPherson, 2004. Menstruation across time: Menarche, menstrual attitudes, experiences and behaviors. Women's Health Issues, $\quad 14$ : 193-200. DOI: 10.1016/j.whi.2004.08.006

McCaffery, M. and A. Beebe, 1993. Pain: Clinical Manual for Nursing Practice. 1st Ed., 1993: Baltimore, Mosby Company, London, ISBN100723419922 pp:320.

Montero, P., C. Bernis, V. Fernandez, S. Castro, 1996. Influence of body mass index and slimming habits on menstrual pain and cycle irregularity. J. Biosoc. Sci., 28: 315-323. DOI: $10.1017 / \mathrm{S} 0021932000022380$

Moronkola, O.A. and V.U. Uzuegbu, 2006. Menstruation: Symptoms, Management and attitude of female nursing students in Ibadan, Nigeria. African J. Reproductive Health, 10: 84-89.

Ohde, S., Y. Tokuda, O. akahashi, H. Yanai and S. Hinohara et al., 2008. Dysmenorrhea among Japanese women. Int. J. Gynecology Obstetrics, 100: 13-17. PMID: 17888923

Ozerdogan, N., D. Sayiner, U. Ayranci, A. Unsal and S. Giray, 2009. Prevalence and predictors of dysmenorrhea among students at a university in Turkey. Int. J. Gynaecol. Obstet., 107: 39-43. DOI: 10.1016/j.ijgo.2009.05.010

Patel, V., V. Tanksale, M. Sahasrabhojanee, S. Gupte and P. Nevrekar, 2006. The burden and determinants of dysmenorrhoea: a populationbased survey of 2262 women in Goa, India. BJOG, 113: 453-63. DOI: $10.1111 / \mathrm{j} .1471-$ 0528.2006.00874.x

Tonnin, G., 2002. Dysmenorrhea, endometriosis and premenstrual syndrome. Minerva Pediatr, 54: 52538. PMID: 12388941

Wang, L., X. Wang, W. Wang, C. Chen and A.G. Ronnennberg et al., 2004. Stress and dysmenorrhoea: A population based prospective study. Occup. Environ. Med., 61: 1021-1026. DOI: 10.1136/oem.2003.012302

Di, W., W. Xiaobin, C. Dafang, N. Tianhua, N. Jiatong et al., 2000. Metabolic gene polymorphisms and risk of dysmenorrhea. Epidemiology, 11: 648-653. 